\title{
The Reasons for College Students' Lack of Humanistic Quality in the New Period
}

\author{
Mi Feng \\ Qiqihar Medical University \\ Qiqihar Heilongjiang Province 161000 \\ Chen Gang \\ Qiqihar Medical University \\ Qiqihar Heilongjiang Province 161000
}

\author{
Song Yaoxin* Corresponding author \\ Qiqihar Medical University \\ Qiqihar Heilongjiang Province 161000
}

\author{
Su Zhenxing \\ Tianjin Medical University \\ Tianjin 300070
}

\begin{abstract}
This paper mainly discusses the lack of humanistic quality of contemporary college students and analyzes its reasons from background, education system and training process. From the strategic point of view, we analyzed the direction and orientation of improvement of humanistic education quality. From the improvement of curriculum setting and education evaluation mechanism, Suggestions on the feasibility of improving the quality of education are proposed to promote the reform and development, and strengthen the construction of university humanistic education.
\end{abstract}

Keywords-College Student; Humanistic Quality; Lack; Reason Analysis

\section{INTRODUCTION}

Humanity quality education in colleges and universities in China has been conducted for a period of time. Although in recent years the humanistic quality education work has been carried out successively in universities, the understanding of the importance of humanistic quality education is far from enough. With the rapid development of social economy, the education appeared the trend of utilitarianism. In this context, colleges and universities tend to pay less attention to carry out the humanistic quality education of students. The weak humanistic quality education, leads to the lack of college students' humanistic quality.

\section{THE LACK OF HUMANISTIC QUALITY OF CONTEMPORARY COLLEGE STUDENTS}

\section{A. Part of students' basic humanistic knowledge is not sufficient}

The specialized training mode has long affected China's higher education, and universities, especially those of science and engineering, pay more attention to professional education, and ignore the humanistic quality education. Under the influence of market economy, the education guidance of quick success and impetuous and superficial academic atmosphere is seriously affecting the cultivation of talents. Under the employment allocation system of colleges' students, employment rate is an important indicator of the teaching

This article is the research production of Heilongjiang Provincial Philosophy and Social Sciences Research and Planning Project "Higher Medical College medical humanities quality training model reform research", approval number: 17EDD180 ability and teaching level of colleges and universities. In order to pursue higher employment rate, some colleges and universities value the cultivation of professional skills and despise the education of humanistic quality.

Ascending humanity quality is one of the requirements of the colleges and universities on cultivating students, but it is common in colleges and universities that their students are lack of humanities quality, don't have solid academic foundation, and have obvious utilitarian tendency. Today's college students spend all the time and energy on learning professional knowledge, and rarely learn humanities knowledge which they pay little attention to. A small number of students will take part in some of the club activities in their spare time, but still pay little attention to traditional culture, and lack of proper understanding of the history of China. Their humanities knowledge is quite poor. [1]

\section{B. Some college students are unbalanced in their cultural and professional quality}

To emphasize science and undervalue humanity refers to paying attention to the training of scientific knowledge and ignoring the education of humanistic knowledge. The concept of emphasizing science and undervaluing humanity forms the education mode of emphasizing science and undervaluing humanity, resulting in the imbalance of students' humanistic quality and professional quality. With the development of education, the problem of the growing weakness of humanistic education is particularly prominent.

Since the modern times, human science and civilization has achieved rapid development, and has also formed the concept of emphasizing science and undervaluing humanity, which makes people more and more ignore the humanities education and results in that the humanistic quality education courses become courses to learn practical knowledge. Science blinds the humanities education's educating on people's emotion, temperament and personality, weakens the aesthetic imagination that humanities education should have had. Science education mode has cultivated the students' cognitive ability, but has lessened the improvement on people's will, spirit, thoughts, values and other deep-level things. 


\section{Most students lack of correct understanding of the negative influence of the network world}

Living in the environment of popularization of information and network, network has become an important tool for contemporary college students to get all sorts of knowledge and information, which has profoundly influenced the students' cognition, psychology, behavior pattern and morality, etc. The positive effects of the network are obvious, but its negative effects can also not be ignored.

The Internet is a double-edged sword. With the increasing popularity of the Internet, college students are becoming more and more affected by the Internet, which brings many problems. The complexity of the network has caused the ideological chaos of college students and has a negative impact on their outlook on life and values. Some college students are addicted to the Internet world and obsessed with games, seriously affecting their studying.

Some college students come into contact with the west socalled freedom, democracy on the Internet, which is not consistent with Chinese traditional culture and the mainstream ideology. It causes their ideological confusion and blindly following without thinking. Network's virtual property has caused the decrease of college students' ability to adapt to the real life and survive in the society. The network world is bizarre and motley, having great temptation to college students whose mental is not entirely mature. Some students have weak self-control ability, and become addicted to virtual world for a long time. Their understanding of the objective world has appeared deviation, resulting in serious psychological problems. Therefore, we must strengthen the humanistic quality education of college students who have poor judgment ability, and strengthen the psychological guidance, so as to reduce the negative impact of the network and play the active role of the network.

\section{Part of student lack of proper moral idea}

Personal morality is very important for college students to be qualified as a pillar of society. Good moral character and strict personal integrity are a great guarantee for a safe and smooth life. But now the problem of moral deviation of college students is becoming more and more serious, and a few students don't regard morality as right. Many college students' thoughts are lost because their moral cognition is off the right track, exposing a lot of ideological and ethical problems. If college students want to develop good moral character, and become the qualified successors to the cause of socialism, it will not just rely on ideological and political education work to solve problems, but also is the embodiment of the humanistic education value.

\section{THE REASONS FOR THE LACK OF HUMANISTIC QUALITY OF CONTEMPORARY COLLEGE STUDENTS}

\section{A. The curriculum of humanistic courses is not reasonable}

The setting of humanistic curriculum in colleges and universities is based on the concept of humanistic quality education of the university. The setting of humanistic quality curriculum should be aimed at cultivating talents with good moral cultivation and personality quality. Therefore, it is important to take the comprehensive harmonious development of human beings as the task of humanities courses. In terms of the content setting of humanistic courses, it is necessary to enhance the richness of course content, broaden the scope of curriculum and establish a diversified curriculum mechanism. To let humanistic spirit penetrate into the teaching of professional courses, in the curriculum implementation, we need to be people-oriented, and start from the interests of students, so as to stimulate students' imagination and creativity, and realize their full scale development. Unfortunately, at present, the humanistic quality education of universities in our country is only just starting, and there are a series of problems such as inadequate humanistic curriculum in both polytechnic and comprehensive universities.

First, many colleges and universities lack the attention to the humanities curriculum. Our country's polytechnic or polytechnic major universities generally have the phenomenon of emphasizing professional and undervaluing humanities. Setup of curriculum system is usually according to the needs of various specialties. Though in the process, the school often claims to adapt to the needs of training comprehensive quality talents, in fact all sorts of practicality and non-professional courses tend to be ignored, especially the humanities courses. The role of humanities courses are hard to quantify.

Second, the scope of humanities curriculum is too narrow. For example, course content is narrow, and many humanities courses are just political science courses. In most universities, only about 10 percent of the curriculum system belongs to the humanities curriculum, of which political theory courses make up the main part, and how many other elective courses can be left?

Thirdly, the content of the humanities course is old and stiff and not lively enough. The humanities courses in many colleges are of antiquated, inflexible and rigid content. Teachers only teach the theory from the book and ignore the practice application, which is lack of practicability and operability, and cannot be used to analyze and solve problems in reality, naturally making students lack of interest to learn. This is not good to improving students' humanistic quality. Only by changing the way of teaching can't change the present situation of insufficient teaching content, therefore, in the humanistic quality education reform we should give full attention on construction of humanities curriculum content, realizing the realistic significance of the humanistic curriculum.

Finally, under the guidance of exam-oriented education and pragmatism, the humanistic quality education of universities is in a weak position. Humanity quality education, in the common sense, is treated as the additional part of other teaching activities, belonging to side branches besides the orthodox course, and need to make way for the formal class at any time. This makes it difficult to conduct effective and sustainable humanistic quality education work. Most universities neglect the education of humanistic spirit, while the human spirit education is the essence of human quality education. Although humanistic quality education becomes a breakthrough point of education reform, it hasn't took its due importance in the entire curriculum system in colleges and universities, and in many 
cases is still taken as supplementary curriculum to let the students choose.[2]

\section{B. The content of humanistic quality education is divorced from reality}

With the gradually carrying out of humanistic quality education in colleges and universities, it has received barely satisfying effect. There are various reasons, and one of the important reasons is that the content of the humanity quality education is divorced from reality, and lack of practicality. Firstly, it fails to combine many ideological content of humanistic quality education with the reality, making it difficult for students to grasp. In terms of cultural heritage, courses with the traditional Chinese culture as the content are not only less but also relatively rough. Student don't have many chances to access to poetry, Qufu, national music, calligraphy, painting, couplets, folk customs in traditional culture, which are also very rarely involved in humanities courses. In the aspect of literature, history, philosophy and art, the humanities courses of many colleges and universities are only based on the theory on books, and rarely combine theory with reality, having little practical significance. Due to the limited appeal of course content, except for students majoring in these specialties, there are few students of other specialties getting to know and learn it. This will be unfavorable for expanding the scope of humanity quality education, increasing students' humanities knowledge, and enhancing their humanistic quality and so on .[3]

\section{The lack of humanities quality education in the professional education}

For a long time, many colleges and universities tend to teach science knowledge, and neglect the humanities knowledge, failing to combine the two organically. This causes the lack of students' humanities quality and cultural atmosphere in schools. Many college students have mastered solid professional knowledge, but their knowledge structure is relatively unitary, and their humanity knowledge is relatively weak. This is precisely because they haven't systematically studied the humanistic knowledge in school. Too much emphasis on professional education makes students' knowledge become single and one-sided, and students' perception and understanding are getting worse and worse.

\section{The evaluation mechanism of humanistic quality has not been established and perfected}

At present, there is a lack of perfect evaluation mechanism for humanistic quality in colleges and universities in China. Under many years' influence of the single evaluation model and the traditional evaluation concept, the scope of evaluation is only limited to simple judgment and identification. In the evaluation of humanistic quality education, many colleges and universities have not established a professional evaluation institution. They rely solely on the teaching department to carry out evaluation activities, with less participation of relevant personnel. In the design of evaluation system, the evaluation form is single, with narrow channels, old evaluation idea and backward means. Many colleges and universities haven't established proper restraint mechanism for the execution of evaluation right, lack of supervision and review mechanism and subject consciousness of automatically perfecting selfbuilding. Even some good system has been designed, it cannot be implemented. Evaluation work become a mere formality, lack of practical assessment effect. The purpose of the evaluation is to find out the shortcomings of education work, continuously improve education quality and level, and provide data support for education reform in the future. Humanities education evaluation, on the basis of the measurement, sets standards and goals, and judges whether standards and goals are achieved through the measurement of education work in a period of time, thus concluding the evaluation of education work results, and providing a reference basis for continuing to improve the education work.[4]

\section{CONCLUSION}

In today's society, with traditional culture becoming increasingly weak, we urgently need to reshape the humanistic spirit, spend more efforts to cultivate professional talents' humanistic quality, so as to make college students more adapt to the development trend of the era, and let people get along with each other more harmoniously.

At present, the curriculum of humanistic quality of colleges and universities in China is not rigorous enough, and the curriculum setting is lack of argumentation and with strong randomness. Therefore, it is one of the tasks of teaching reform in colleges and universities to bridge the disciplinary boundaries, strengthen the penetration of the humanistic spirit to the professional courses, and increase the proportion of the humanities courses in the curriculum system. Only in this way can the course system of the university be transformed into a comprehensive and balanced direction, which is also in line with the requirements and goals of education. The rich and colorful humanities curriculum is an important resource to enhance the humanistic spirit of students, and it is of great practical significance to improve the quality of humanities courses to the improvement of the teaching quality of colleges and universities. Perfect education evaluation mechanism plays an important role in improving the level of humanistic education. We need to set scientific and reasonable standard and flexible form for teaching assessment system, and this is also the inevitable choice for colleges and universities to strengthen own construction and promote the reform and development.

\section{REFERENCES}

[1] M. Du Shizhong. Humanistic Education, Jiangsu education press, 1999. (In Chinese)

[2] M. Zhong Binglin. The Direction of the University, Commercial press, 2015. (In Chinese)

[3] M. Wu Jinqiu. Innovation and Entrepreneurship Education in Chinese Universities, Heilongjiang people's publishing house, 2013. (In Chinese)

[4] M.Zhang Xiangyun. University Education Returns to Humanity, Sun yat-sen University Press, 2004. (In Chinese) 